\title{
Máscaras, flores e divinos: a cultura material da Festa do Espírito Santo de Pirenópolis/GO
}

\author{
Masks, flowers and divines: the material culture \\ of the Feast of the Holy Spirit in Pirenópolis (Goiás, Brazil) \\ Amanda Alexandre Ferreira Geraldes \\ Mestranda em História na PUC-SP - Bolsista do CNPq \\ amandaalexandre@gmail.com
}

Resumo

A Festa do Divino Espírito Santo da cidade de Pirenópolis, no estado de Goiás, ocupa um espaço especial no imaginário coletivo da comunidade. Neste artigo, cuja pesquisa se encontra em desenvolvimento para a elaboração da dissertação de mestrado, iremos apresentar uma breve descrição dos tempos da festa e as muitas formas de celebrar o Divino. A pesquisa propõe analisar objetos da cultura material produzidos para a festa e busca identificar a relação estabelecida entre os significados dos símbolos e suas representações na coletividade da comunidade. Para tanto, entendemos que os saberes, as artes de fazer e a tradição são sustentados por uma memória e constroem identidades coletivas e individuais. A escolha metodológica parte do trabalho com fontes da Cultura Material, História Oral e Iconografia.

Palavras-Chave: Festas. Memória. Cultura Material.

\section{Abstract}

The Feast of the Divine Holy Spirit in the city of Pirenópolis, in the state of Goiás (Brazil), occupies a special place in the collective imaginary of the community. In this article, whose research is being developed for the preparation of the Master's thesis, we will present a brief description of the times of the feast and the many ways of celebrating the Divine. The research aims to analyze objects of material culture produced for the feast and seeks to identify the relation between the meanings of the symbols and their representations in the collectivity of the community. Therefore, we believe that knowledges, arts of making and the tradition are supported by a memory and builds collective and individual identities. The methodological choice part of the work with sources of Material Culture, Oral History and Iconography.

Keywords: Celebrations. Memory. Material Culture. 
A Festa do Divino Espírito Santo de Pirenópolis é uma festa religiosa que acontece tradicionalmente na cidade desde 1819. Consolidando sua relevância e sua memória, a celebração obteve pelo IPHAN, em 2010, o registro como Patrimônio Cultural Imaterial, sendo então a segunda manifestação registrada no Livro das Celebrações, na qualidade de bem imaterial, realizada no país. A festa tem duração de quase dois meses, mas seu auge acontece no Domingo de Pentecostes, 50 dias após a Páscoa, data que representa a vinda do Divino Espírito Santo sobre os apóstolos de Cristo. Essa data marca na festa o início das famosas Cavalhadas - uma encenação que representa a luta dos cristãos liderados por Carlos Magno nas Cruzadas contra os mouros. De origem medieval, a celebração chegou ao Brasil na época colonial, prestando-se como forma de catequização e expressão religiosa.

Celebrar Pentecostes é parte da liturgia católica. A Festa do Divino é uma celebração muito comum em todo o país, no entanto, em Pirenópolis, a festa tem suas particularidades. São muitas as manifestações que compõem as comemorações ao Divino: além do Império do Divino, lá encontramos as folias, as novenas, as missas e as procissões, as pastorinhas, as cavalhadas e os mascarados, as congadas e os congos, as bandas de música, os reinados e juizados. É uma festa de grande porte, que reuniu ao longo do tempo todas essas manifestações para celebrar o Divino.

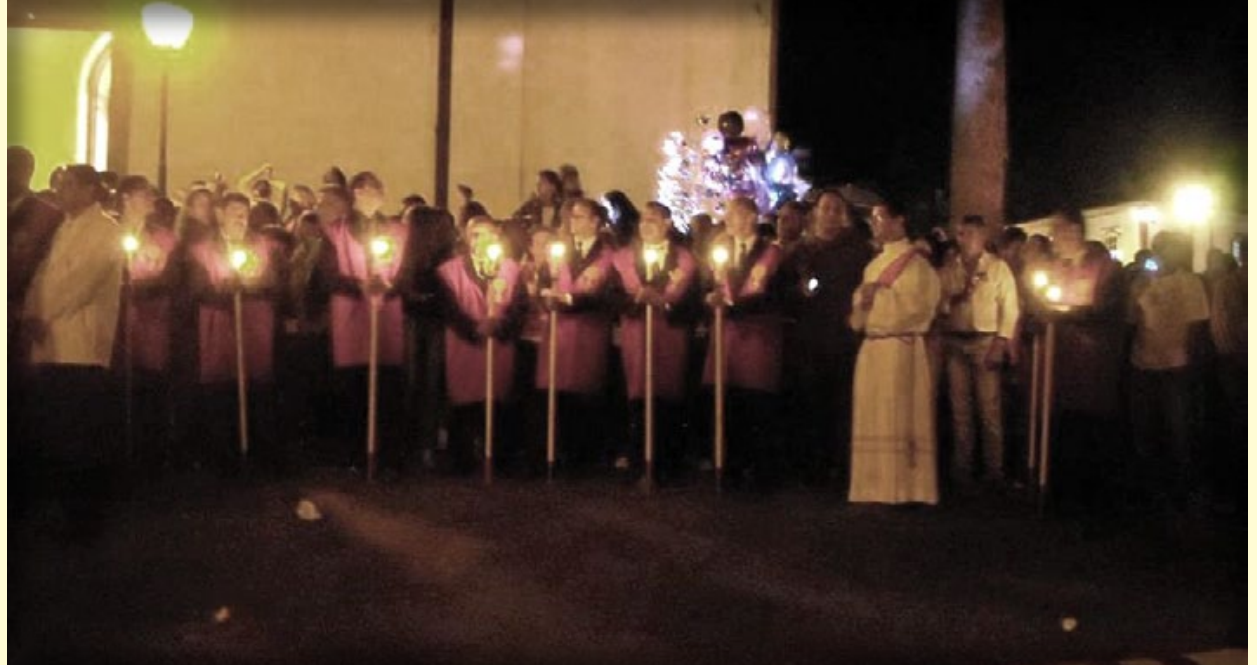

Benção e levantamento do Mastro, 2012. Foto: Amanda Alexandre e Antonio Bandeira

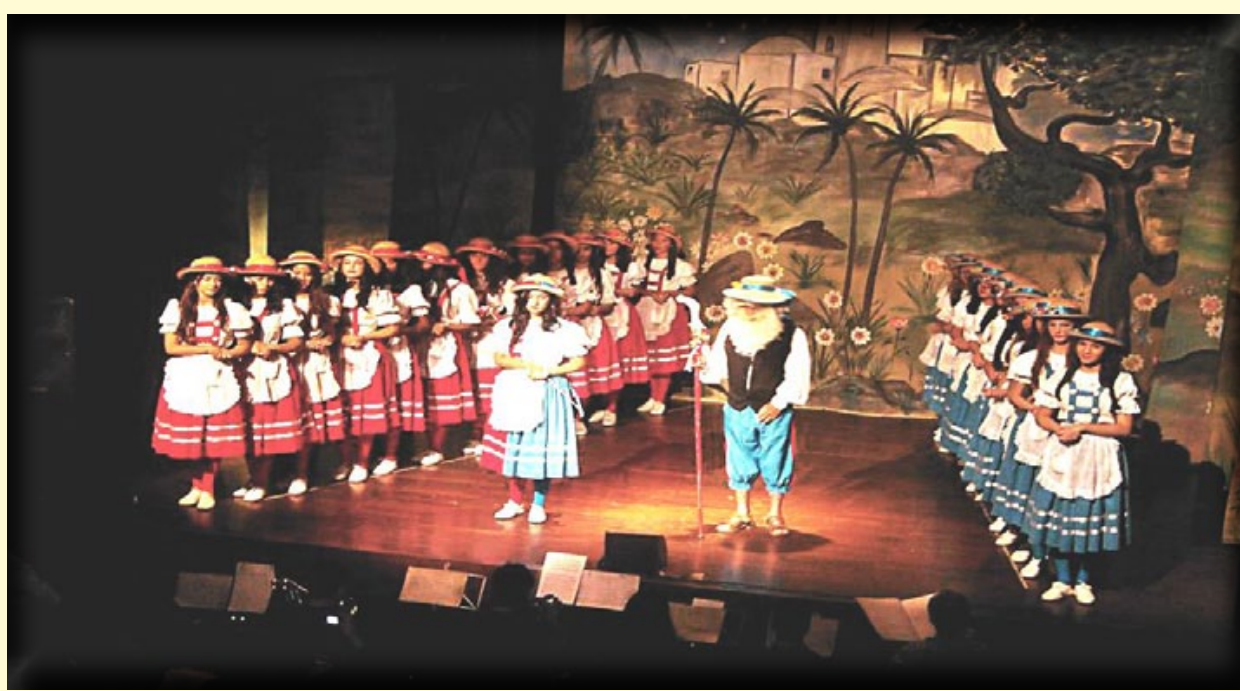

Auto natalino “As Pastorinhas", 2012. Foto: Amanda Alexandre e Antonio Bandeira

\section{Os Tempos da Festa e as Festas Dentro da Festa}

O cronograma da festa é complexo: cerca de 20 dias antes de Pentecostes iniciam as Folias do Divino Espírito Santo ${ }^{1}$. Atualmente, são dois grupos de folias que fazem os giros e os pousos: a "folia do povo" e a "folia do padre", essa organizada pela Paróquia Nossa Senhora do Rosário - local onde se concentram as atividades religiosas da festa. As folias (que podem ser rural e urbana) saem e chegam em datas diferentes e têm cerca de dez dias de duração cada uma. Por volta de 15 dias antes do domingo de Pentecostes, iniciam os ensaios dos cavaleiros das Cavalhadas. Faltando nove dias para o domingo de Pentecostes inicia-se a Novena do Divino Espírito Santo, sempre numa sexta-feira. O início da novena marca no calendário oficial, a "abertura" da festa. Durante os nove dias de novena, a cidade amanhece com duas alvoradas - a primeira às 4 horas, com a banda de Couro, e a segunda às 5 horas, com a tradicional banda Phôenix. Fogos e roqueiras são disparados nesses nove dias de alvorada que se seguem com a missa e a novena, já no período noturno, às 19 horas. No último dia da novena - sábado, véspera de Pentecostes - ocorre

1 As Folias mais tradicionais partem a cavalo, percorrendo um trajeto pelas fazendas da zona rural da cidade. Com o objetivo de recolher donativos para a festa, os foliões fazem os giros com a bandeira do Divino, acompanhados pela comunidade que participa do evento e pelos anfitriões da casa que oferecem o pouso e o alimento. A dinâmica alimentar é característica primordial no processo das folias, constituindo um ato de fé e um comportamento festivo compartilhados socialmente. 
a procissão dos membros da Irmandade do Santíssimo Sacramento ${ }^{2}$ para a bênção e o levantamento do mastro, acontecendo em seguida a tradicional queima de fogos e a apresentação do auto de natal "As Pastorinhas", no teatro da cidade. É também no sábado do Divino que os mascarados saem pelas ruas da cidade, anunciados pelos seus guizos e fazendo brincadeiras, trazendo à festa alegria, irreverência e o colorido de suas máscaras e flores de papel.

É chegado o dia mais esperado: o Domingo de Pentecostes. Após as alvoradas, segue o Cortejo Imperial, saindo da casa do Imperador ${ }^{3}$ rumo à igreja. Depois da missa é realizado o sorteio do próximo Imperador e dos mordomos. Terminado o sorteio, um novo cortejo sai da igreja rumo à casa do atual imperador. Nesse cortejo, seguem: o Imperador e sua família, ocupando lugar de honra na procissão, a Irmandade do Santíssimo Sacramento, a Procissão das Virgens (meninas vestidas de branco), as bandas de Couro e Phôenix e, por fim, a comunidade que acompanha para receber do Imperador os cumprimentos e as tão esperadas Verônicas de Alfenim e os pãezinhos do Divino ${ }^{4}$. $\mathrm{Na}$ casa do Imperador, fica exposto o altar em homenagem ao Divino, exibindo a Bandeira, a Coroa e o Cetro - símbolos do Espírito Santo.
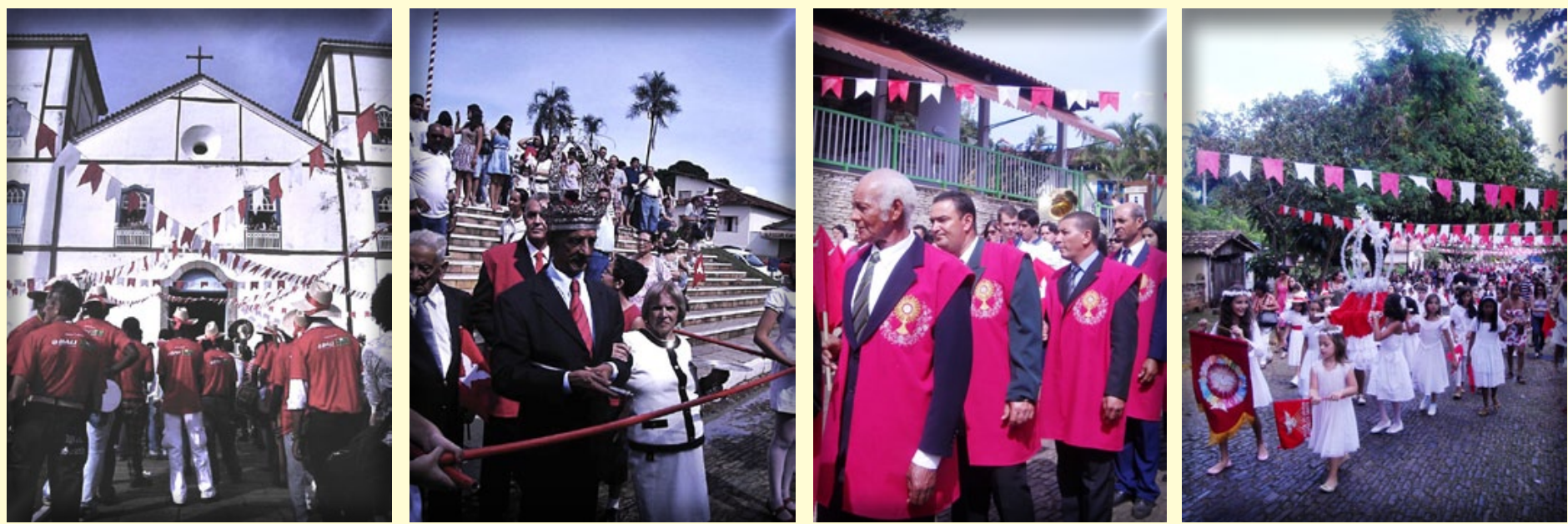

Da esq. para dir.: 1 - Chegada do Cortejo Imperial à Igreja, 2012; 2 - Saída do Cortejo Imperial após a missa, 2012 ; 3 e 4 - Procissão das Virgens no Cortejo Imperial, 2012. Fotos: Amanda Alexandre e Antonio Bandeira
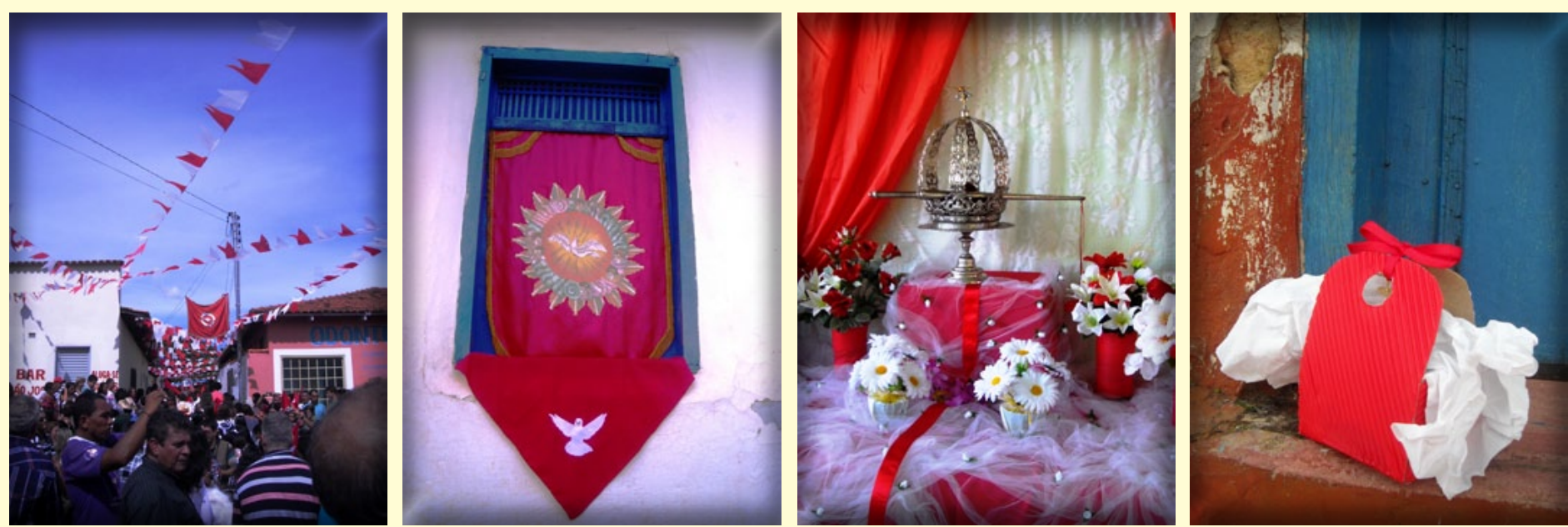

Da esq. para dir.: 1 - Chegada do cortejo à casa do Imperador, 2012; 2 - Bandeira do Divino em residência, $2012 ; 3$ - Altar do Divino na casa do Imperador, 2012; 4 - Embalagem com as Verônicas de Alfenim e os pãezinhos do Divino, 2012. Fotos: Amanda Alexandre e Antonio Bandeira.

2 A Irmandade do Santíssimo Sacramento foi criada em 1732 e constitui-se como um grupo de devotos que preservam os valores religiosos, promovendo solenidades e encontros relacionados à fé cristã e cuidando dos bens e interesses da igreja.

3 O Imperador é o festeiro, figura responsável pela administração e divulgação da festa. Ele representa grande autoridade e status, pois foi escolhido pelo Divino para ocupar tal posição de honra e carregar seus símbolos do Império: a coroa e o cetro.

4 Quando o cortejo chega à casa do Imperador, as bandas entram para a área preparada para o evento (geralmente um pátio ou a área externa da casa) que é onde fica o altar ao Divino. Todas as pessoas que participaram da procissão se organizam em uma fila para receber as lembrancinhas. A banda toca o Hino do Divino e após esse momento os familiares do festeiro começam a distribuir as verônicas, que são doces feitos de açúcar - o alfenim, uma massa branca e muito delicada - que são trabalhadas à mão e moldadas em formato circular com motivos do Divino, e os pãezinhos do Divino, ambos embalados especialmente para a ocasião. 
Esses objetos possuem um status sacro: na procissão as pessoas debruçam para tocá-los e pedir graças. Todas essas atividades - que iniciaram às 4 horas da manhã - se prolongam até o horário do almoço. E é preciso estar atento: a abertura das Cavalhadas começa às 13 horas no campo conhecido como "Cavalhódromo". Durante toda a tarde do domingo acontece o primeiro dos três dias de encenação das Cavalhadas. Ainda no domingo, na missa à noite, temos a posse do novo Imperador, que com os mordomos, já começam a pensar os preparativos para a festa do próximo ano. $\mathrm{O}$ novo ciclo se inicia antes mesmo que o ciclo corrente termine.
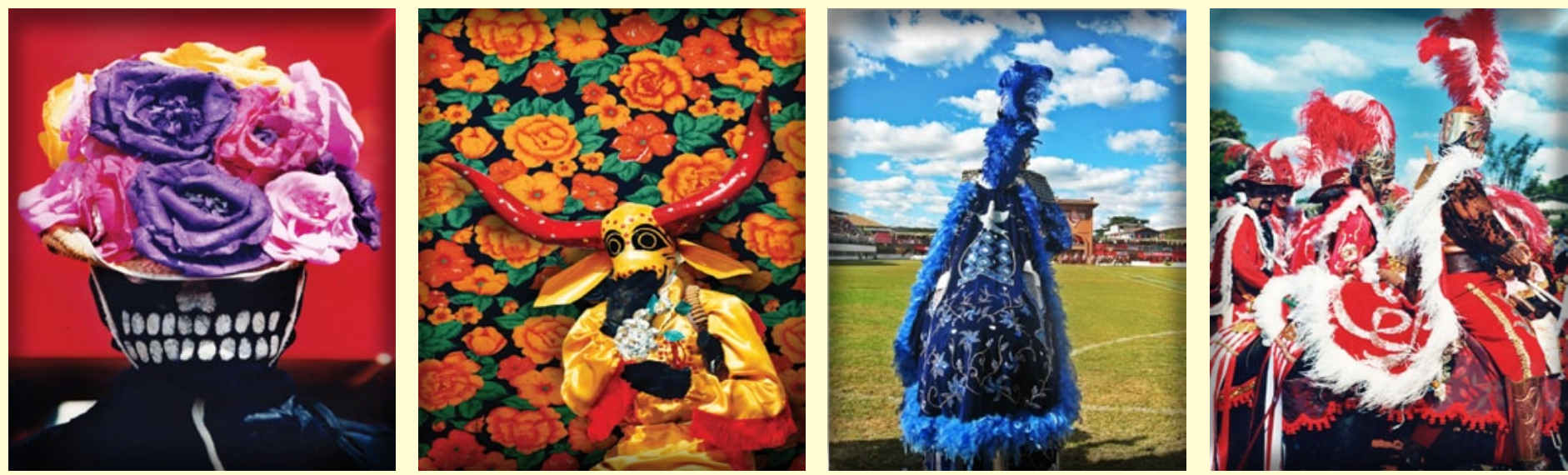

Da esq. para dir.: 1 - Mascarado - A morte de chapéu, 1992; 2 e 3 - Mascarado Curucucu, $1992 ; 4$ - Rei e Cavaleiros Mouros, 1992. Fotos: Amanda Alexandre e Antonio Bandeira.

A segunda-feira começa com o Reinado de Nossa Senhora do Rosário: o cortejo, a missa e a festa do Reinado - os reinados e juizados seguem a mesma estrutura dos cortejos do Imperador do Divino: o cortejo busca o rei e a rainha em sua residência, seguindo para a igreja onde acontecerá a missa. Após a missa o cortejo retorna da igreja para a residência do rei e rainha onde acontece a "festa" e são servidos os quitutes para a comunidade. Esse movimento ocupa todo o período da manhã e às 13 horas dá-se continuidade ao segundo dia da encenação das Cavalhadas. Na terça-feira, acontece o Juizado de São Benedito - nos mesmos moldes do Reinado - e no período da tarde o último dia das Cavalhadas. A festa termina oficialmente em meados de junho, no dia de Corpus Christi, data em que o mastro é descido e se comemora o encerramento da festa com um grande almoço, que é oferecido para todos os envolvidos na festa. E nesse mesmo final de semana, ainda acontecem na cidade as Cavalhadinhas Mirins, onde as crianças participam e atuam, nos mesmos moldes da festa ocupada pelos adultos.

\section{Memória e Representação na Cultura Material}

É interessante observarmos alguns aspectos na dinâmica da festa: 1. como a memória é construída na vida cotidiana coletiva e nos ritos da festa; 2. como é estabelecido o calendário das atividades de produção dos objetos da cultura material; 3. a teatralidade que reveste toda a dinâmica dos ritos e representações; 4. as relações de poder e suas tensões que são mascaradas pela ordem própria da festa; 5 . a dominação simbólica presente na cultura material. Para compreender esses aspectos apontados, primeiro precisamos pensar nos conceitos das palavras-chave que norteiam o trabalho.

Buscamos conceituar a festa para compreender melhor as relações entre a dinâmica dessa prática social e a produção da cultura material. Fundamentamos em Bakhtin esse conceito, uma vez que se tratando de uma festa religiosa, nota-se a profunda relação com o sagrado nas manifestações e suas representações. Segundo Bakhtin, a festa é algo maior que a experiência puramente humana:

As festividades (qualquer que seja o seu tipo) são uma forma primordial, marcante, da civilização humana. Não é preciso considerá-las nem explicá-las como um produto das condições e finalidades práticas do trabalho coletivo nem, interpre-

5 Cavalhódromo é o espaço onde se encena a performance das Cavalhadas. Foi construído especialmente para esse fim e sua inauguração é recente, em 2006. Essa mudança, consequentemente, alterou toda a cartografia da festa e também a relação do público x espetáculo e toda essa dinâmica presente no ritual. 
tação mais vulgar ainda, da necessidade biológica (fisiológica) de descanso periódico. As festividades tiveram sempre um conteúdo essencial, um sentido profundo, exprimiram sempre uma concepção do mundo. Os "exercícios" de regulamentação e aperfeiçoamento do processo do trabalho coletivo, o "jogo no trabalho", o descanso ou a trégua no trabalho nunca chegaram a ser verdadeiras festas. Para que o sejam, é preciso um elemento a mais, vindo de uma outra esfera da vida corrente, a do espírito e das ideias. A sua sanção deve emanar não do mundo dos meios e condições indispensáveis, mas daquele dos fins superiores da existência humana, isto é, do mundo dos ideais. Sem isso, não pode existir nenhum clima de festa. (BAKHTIN, 1987: 7-8)

Entendemos a festa como uma expressão fundamental presente na dinâmica cultural. Sua ordem própria revela concepções de mundo e, no âmbito religioso, pensamos na relação metafísica existente que desenvolve na comunidade vivências de profundo respeito, devoção e sacralização, culminando em verdadeiras experiências de contato com o sublime.

A cultura material é o suporte material físico de reprodução da vida social e que é apropriado socialmente pelo homem. Por apropriação social entendemos como uma intervenção humana, segundo padrões e normas culturais, sendo essa ação coletiva e não aleatória ou individual. Esses artefatos, no entanto, precisam ser considerados em duas vias: como produtos e como vetores de relações sociais, cumprindo ambas funções: como resultado de práticas sociais, mas também como possibilitadores de novas relações sociais. (Bezerra de Meneses, 1983: 112-113). A abordagem da cultura material é, portanto, um campo de reflexão que é associado a uma fonte, um objeto, um suporte material que é utilizado para compreender as práticas sociais, mas que, no entanto, não se limita a esse artefato.

E qual a relação que podemos estabelecer entre cultura material e memória? Naturalmente existe uma tradição, provavelmente oral, na transmissão dos saberes quanto à feitura desses objetos. Podemos também pensar numa memória coletiva relacionada aos artefatos e ao espaço material que os cercam. Para tanto, Halbwachs explica que:

Assim, não há memória coletiva que não aconteça em um contexto espacial. Ora, o espaço é uma realidade que dura: nossas impressões se sucedem umas às outras, nada permanece em nosso espírito e não compreenderíamos que seja possível retomar o passado se ele não estivesse conservado no ambiente material que nos circunda. É ao espaço, ao nosso espaço - o espaço que ocupamos, por onde passamos muitas vezes, a que sempre temos acesso e que, de qualquer maneira, nossa imaginação ou nosso pensamento a cada instante é capaz de reconstruir - que devemos voltar nossa atenção, é nele que nosso pensamento tem de se fixar para que essa ou aquela categoria de lembranças reapareça. (Halbwachs, 2006: 170)

Pensando no espaço da cidade de Pirenópolis e também na cartografia da festa, podemos afirmar que tal relação espaço-memória coletiva se dá quase naturalmente na rotina da comunidade, uma vez que a cidade carrega uma história em suas ruas calçadas de pedra, nas paredes das casinhas do século XVIII e em todo o festejo ao Divino. Perceber a cidade também como objeto de cultura material faz parte da dinâmica, pois não podemos nos esquecer que a cidade propriamente é material. Os objetos materiais também são responsáveis na construção dessa memória. Os saberes e os fazeres permeiam o cotidiano e possuem um calendário específico que antecede o calendário das celebrações. A proposta de identificar quais as representações estabelecidas nos objetos da cultura material se baseia na compreensão defendida por Gonçalves:

$\mathrm{Na}$ medida em que os objetos materiais circulam permanentemente na vida social, importa acompanhar descritiva e analiticamente seus deslocamentos e suas transformações (ou reclassificações) através dos diversos contextos sociais e simbólicos. [...] Acompanhar o deslocamento dos objetos ao longo das fronteiras que delimitam esses contextos é em grande parte entender a própria dinâmica da vida social e cultural, seus conflitos, ambiguidades e paradoxos, assim como seus efeitos na subjetividade individual e coletiva. (Gonçalves, 2007: 15)

Assim, buscamos analisar as transformações desses objetos ao longo do tempo e quais são as representações e os significados simbólicos que esses carregam em cada tempo-espaço compreendido. Além da relação do espaço com a construção de uma memória coletiva, temos nesse acervo vivo de memória um importante aspecto: as identidades que são construídas e sustentadas, tanto individualmente quanto coletivamente:

A memória é base construtora de identidades e solidificadora de consciências individuais e coletivas. É elemento constitutivo do autorreconhecimento como pessoa e/ou como membro de uma comunidade pública, como uma nação, ou 
privada, como uma família. A memória é inseparável da vivência da temporalidade, do fluir do tempo e do entrecruzamento de tempos múltiplos. A memória atualiza o tempo passado, tornando-o tempo vivo e pleno de significados no presente. (Delgado, 2010: 38)

Essas distinções em grupos privados podem ser atribuídas ao caráter da festa aos papéis que cada pessoa/grupo representa na "encenação" ritualística apresentada. Recorremos ao conceito de representação proposto por Chartier para entender como essa base teórica se aplicaria no trabalho proposto:

\begin{abstract}
Assim construido, o conceito de representação foi e é um precioso apoio para que se pudessem assinalar e articular, sem dívida, melhor do que nos permitia a noção de mentalidade, as diversas relaçöes que os indivíduos ou os grupos mantêm com o mundo social: em primeiro lugar, as operaçoes de classificação e hierarquização que produzem as configuraçoes múltiplas mediante as quais se percebe e representa a realidade; em seguida, as práticas e os signos que visam a fazer reconhecer uma identidade social, a exibir uma maneira própria de ser no mundo, a significar simbolicamente um status, uma categoria social, um poder; por último, as formas institucionalizadas pelas quais uns "representantes" (indivíduos singulares ou instâncias coletivas) encarnam de maneira visivel, "presentificam" a coerência de uma comunidade, a força de uma identidade ou a permanência de um poder. A noção de representação, assim, modificou profundamente a compreensão do mundo social. (Chartier, 2011: 20)
\end{abstract}

A cultura material e suas representações se significam na prática. Essa teatralidade encontrada nos ritos da festa desempenha distintos papéis e funções sociais. Para compreender o que cada um representa, precisamos identificar os cenários, os atores e seus papéis na festa. Compondo essa teatralidade, os objetos representam, portanto, simbolicamente um status na dinâmica da festa. São poderes invisíveis que correspondem a uma dominação, que segundo Bourdieu:

É enquanto instrumentos estruturados e estruturantes de comunicação e de conhecimento que os sistemas simbólicos cumprem sua função política de instrumentos de imposição ou de legitimação da dominação, que contribuem para assegurar a dominação de uma classe sobre outra (violência simbólica) dando o reforço da sua própria força às relações de força que as fundamentam e contribuindo assim, segundo a expressão de Weber, para a domesticação dos dominados. (BOURDIEU, 2011: 11)

Entendemos os sistemas simbólicos de Bourdieu na festa quando percebemos tensões presentes na dinâmica social, mas que, no entanto, são mascaradas, de certa forma, na prática festiva. Não atribuímos esse caráter da dominação simbólica a uma estrutura de separação da comunidade em classes ou conflitos visíveis durante a festa, até porque toda a manifestação ao Divino tem uma característica muito forte de união em toda a comunidade, contudo, os símbolos representados pela cultura material são claramente divididos em funções e aspectos muito delimitados para cada grupo e para cada atuação no cenário da festa. Podemos exemplificar essa questão com o fato de o próprio sorteio do Imperador e dos Mordomos exigir padrões e regras sociais e de valores religiosos específicos para participação, que são regulamentados pela Irmandade do Santíssimo Sacramento. Atualmente, o sorteio é restringido aos membros desta Irmandade.

\title{
Os Saberes e as Artes de Fazer
}

Os saberes, as artes de fazer e a tradição são sustentados por uma memória e constroem identidades coletivas e individuais. Por saberes, entendemos como as táticas dos modos de saber e das artes de fazer os objetos da cultura material. Permeando a tradição, a oralidade e o cotidiano, "essas maneiras de fazer constituem as mil práticas pelas quais usuários se reapropriam do espaço organizado pelas técnicas da produção sociocultural." (Certeau, 1994: 41). Assim, entendemos que na produção da cultura material não há técnica e não há transmissão se não houver tradição. (Mauss, 2003: 407). Dessa forma, buscamos compreender as relações estabelecidas entre a memória e a tradição e como são construídas as identidades coletivas e individuais. Gonçalves explica que “enquanto 'objetos cerimoniais', eles não apenas demarcam posições sociais, mas permitem que os indivíduos e os grupos sociais percebam e experimentem subjetivamente suas posições e identidades como algo tão real e concreto quanto os objetos materiais que os simbolizam". (Gonçalves, 2007: 21), portanto, ao analisar as representações simbólicas dos objetos, identificamos o sistema simbólico do grupo. 
Segundo Lemonnier (apud Zuse, 2008):

As escolhas técnicas são representações sociais que formam uma tecnologia ou uma ação tecnológica; são componentes do grande sistema simbólico e indicadores de significados e símbolos. São opções adotadas pelos artesãos, de maneira consciente ou inconsciente, como a escolha de usar ou não certos materiais disponíveis, dos instrumentos a ser utilizados numa ação técnica, a escolha dos processos tecnológicos - conjunto de ações e seus efeitos sobre a matéria - e os resultados desses processos, a escolha de como a ação deve ser executada. (Lemonnier, 1992: 5)

Esse imaginário participa diretamente no desenvolvimento dos produtos culturais utilizados na festa. Para compreender a produção dessa cultura material, iremos investigar a construção desse imaginário. A memória sustenta a tradição e a continuidade da Festa do Divino. Propomos registrar os saberes que constituem essa memória coletiva para compreender a construção identitária nas manifestações. Bosi diz que "na maior parte das vezes, lembrar não é reviver, mas refazer, reconstruir, repensar, com imagens e ideias de hoje, as experiências do passado. A memória não é sonho, é trabalho" (Bosi, 1994: 55). Para isso, propomos verificar as experiências nas "memórias dos velhos" que participam da festa tradicionalmente para construir um memorial comparativo da festa, que seria um inventário de memórias para registro e análise desse corpus documental da memória oral, possibilitando assim um comparativo das memórias ao longo do tempo.

\section{Referências Bibliográficas}

BAKHTIN, Mikhail Mikhailovitch. A cultura popular na Idade Média e no Renascimento: o contexto de François Rabelais. São Paulo: Hucitec; Brasília: Editora da Universidade de Brasília, 1987.

BEZERRA DE MENESES, Ulpiano T. A cultura material no estudo das sociedades antigas. In: Revista de História no 115, p. 103-117, 1985.

BOURDIEU, Pierre. O poder simbólico. 15a edição. Rio de Janeiro: Bertrand Brasil, 2011.

BOSI, Ecléa. Memória e Sociedade - Lembranças de Velhos. São Paulo: Companhia das Letras, 1994.

CERTEAU, Michel de. A invenção do cotidiano: 1. Artes de fazer. $2^{a}$ edição. Petrópolis, Rio de Janeiro: Vozes, 1994.

A invenção do cotidiano: 2. Morar, cozinhar. Petrópolis, Rio de Janeiro: Vozes, 1996.

CHARTIER, Roger. Defesa e ilustração da noção de representação. Fronteiras, Dourados, MS, v. 13, n. 23, jan./jun. 2011.

DELGADO, Lucilia de Almeida Neves. História oral - memória, tempo, identidades. $2^{\mathrm{a}}$ edição. Belo Horizonte: Autêntica, 2010.

GONÇALVES, José Reginaldo Santos. Antropologia dos objetos: coleções, museus e patrimônio. Rio de Janeiro, Depto de Museus e Centro Culturais, 2007.

HALBWACHS, Maurice. A Memória Coletiva. São Paulo: Centauro, 2006.

LEMONNIER, Pierre. Elements for an Anthropology of Technology. Ann Arbor: Michigan, 1992.

MAUSS, Marcel. Sociologia e Antropologia. São Paulo: Cosac Naify, 2003.

ZUSE, Silvana. Cerâmica Guarani e de Contato: Permanências e Mudanças Técnicas em uma Redução Jesuítica do Início do século XVII. In: Anais do IX Encontro Estadual de História, ANPUH-RS, 2008. 